\section{COVID-19 Era: Mondor's disease and Rembrandt. What ties?}

\author{
Giovanni B. Agus \\ Vascular Surgery, University of Milan, \\ Italy
}

\begin{abstract}
The recent and increased number of scientific reports on venous thrombosis and venous thromboembolism induced by corona-virus, suggests to improve our level of attention because thrombophlebitis could be a clinical manifestation of COVID-19. We need to be aware also of rare varieties of venous thrombosis such as Mondor disease. The comparison between the enigmatic breast discoloration of the Bathsheba painted by Rembrandt and a case of Mondor disease observed in 2020 , becomes a cultural game to improve our clinical skills in diagnosing Mondor thrombophlebitis.
\end{abstract}

\section{Commentary}

Personally, and immediately I tie the name of Henri Mondor to Jacques Oudot, one of the biggest pioneers in vascular surgery. Oudot was pupil and first assistant of Professor Mondor, a French surgeon, in Paris in the 1950, the year of the first aortic revascularization made by him. Here we remember the eponymic vascular disease called as Mondor's disease. This kind of thrombophlebitis was described by Henri Mondor that reported in detail a case series in $1939^{1,2}$ in this way: tronculite souscutanée subaiguë de la paroi thoracique antérolatérale. It clinically manifested as palpable subcutaneous cord-like indurations beneath the skin on the chest wall along front axillary line. Subsequently, similar cord-like indurations occurring at the abdominal wall, groin, axilla, and penis were also reported. Although no formal classification has yet been established, Mondor's disease on the anterolateral thoracoabdominal wall is generally recognized as original aspect, while similar abnormalities on other sites, such as the penis and axilla, are recognized as variants. The former is called Mondor's penile disease, first reported by Helm et al. in $1958,{ }^{3}$ and the latter is called axillary web syndrome, first reported as a complication of axillary surgery by Moskovitz et al. in $2001 .{ }^{4}$ Almost all cases of Mondor's disease are reported to be thrombophlebitis of the superficial vein, although some are reported to be lymphangitis and/or a combination of both the etiologies. $^{5}$ In our years, various authors have proposed some new etiologies; however, the clinical course of the disease remains unchanged. It wasn't rare to observe in vascular office visits and were diagnosed as having Mondor's disease. Although Mondor's disease is not a precancerous lesion, patients with atypical clinical courses should undergo close follow-up. ${ }^{6}$ Cases of Mondor's disease associated with carcinoma of the breast was reported. Forked string and triple beads have been reported previously in this disease and sometime one of the beads of triple beads can be malignant. It is suggested that biopsy and histologic examination are the best course of action for Mondor's disease associated with beads. ${ }^{7}$ An excellent review on the epidemiology, etiology, pathophysiology, symptomatology, diagnosis, management, and prognosis is available. ${ }^{8}$

A famous Rembrandt's picture Bathsheba at her bath as painted by Rembrandt van Rijn in 1654 -, is a curious example of discussion about Mondor's disease for the presence of a raised bluish discoloration on Bathsheba's left breast, lateral to the areola (Figure 1).

This picture represents Rembrandt's life-stable partner, Hendrickje Stoffels, when he became widower. Evidently, she had some condition affecting her breast. Braithwaite and Shugg ${ }^{9}$ suggested that the most probable diagnosis was breast cancer, interpreting the skin lesion as peau d'orange, a typical sign of breast cancer infiltrating the skin. To further support their hypothesis, they drew attention to the expression of sorrow and resignation on the model's face, and the short life of Hendrikje, who died 9 years after posing for the painting. But they don't consider the events of Hendrikje and Rembrandt's life. The connection with the face of Hendrikje is referred to their dramatic financial situation that prevented them from getting married, to avoid Rembrandt's creditors, and is reflected right in Bathsheba's painting, where the painful passivity of facial expression contrasts with the beauty of her thriving young body. It will always be the beautiful model for the paintings and for engravings pervaded of erotic feelings that Rembrandt had no longer realized since the years of Danae in 1647. Given that Hendrikje was rather young to have developed breast cancer, being 23 years old, Bourne proposed she had tuberculous mastitis - less rare in the $17^{\text {th }}$ century than today
Correspondence: Giovanni B. Agus, Vascular Surgery, University of Milan, Italy.

E-mail: agus.gb@fastwebnet.it

Key words: COVID-19; venous thrombosis; thrombophlebitis; Mondor disease; art and medicine.

Received for publication: 14 May 2020. Accepted for publication: 14 May 2020

This work is licensed under a Creative Commons Attribution 4.0 License (by-nc 4.0)

C Copyright: the Author(s), 2020

Licensee PAGEPress, Italy

Veins and Lymphatics 2020; 9:9107

doi:10.4081/vl.2020.9107

- or chronic lactational abscess. ${ }^{10}$ Hayakawa et al. also suggested lactational mastitis following miscarriage or premature childbirth without breast feeding. ${ }^{11}$ Finally, Paolo Zamboni from University of Ferrara, Italy, both excellent doctor and good connoisseur of art, considering alternative diagnoses propose very recently that Rembrandt may have depicted thrombophlebitis of a superficial vein, ${ }^{12}$ a condition described by Mondor in 1939, as well known. For coincidence, just a few days after his musings, a male nurse knocked on his office door and, clearly alarmed, asked to be examined. Zamboni saw on his right breast something closely similar to what is present in Bathsheba's left breast (Figure 2). Ultrasound confirmed the diagnosis of thrombophlebitis of the thoraco-epigastric vein and in addition, revealed a tributary vein a few millimeters below the skin surface, just at the level of the breast discoloration. Mammography was performed because Mondor disease may be associated with breast cancer, and resulted negative both for cancer and mastitis. Based on these comparative findings Zamboni, entering as an art critic, proposed that Rembrandt depicted Mondor's disease in his partner's breast.

What ties thrombophlebitis with COVID-19? Evidently little if it is considered this kind of thrombophlebitis in the general epidemiology, but we think that vascular alterations in the pandemic disease was underestimated by many doctors and overall virologists. Vascular general experience proposes more attention to this because SARS-CoV-2 may predispose patients to thrombotic disease, both in the venous and arterial circulations, due to excessive inflammation, platelet activation, endothelial dysfunction, and stasis, ${ }^{13}$ in 
addition with personal experience in a pilot registry in patients treated at home. ${ }^{14}$ Previous studies on SARS-CoV had already taught us that lactoferrin colocalizes with the widely distributed cell-surface heparan

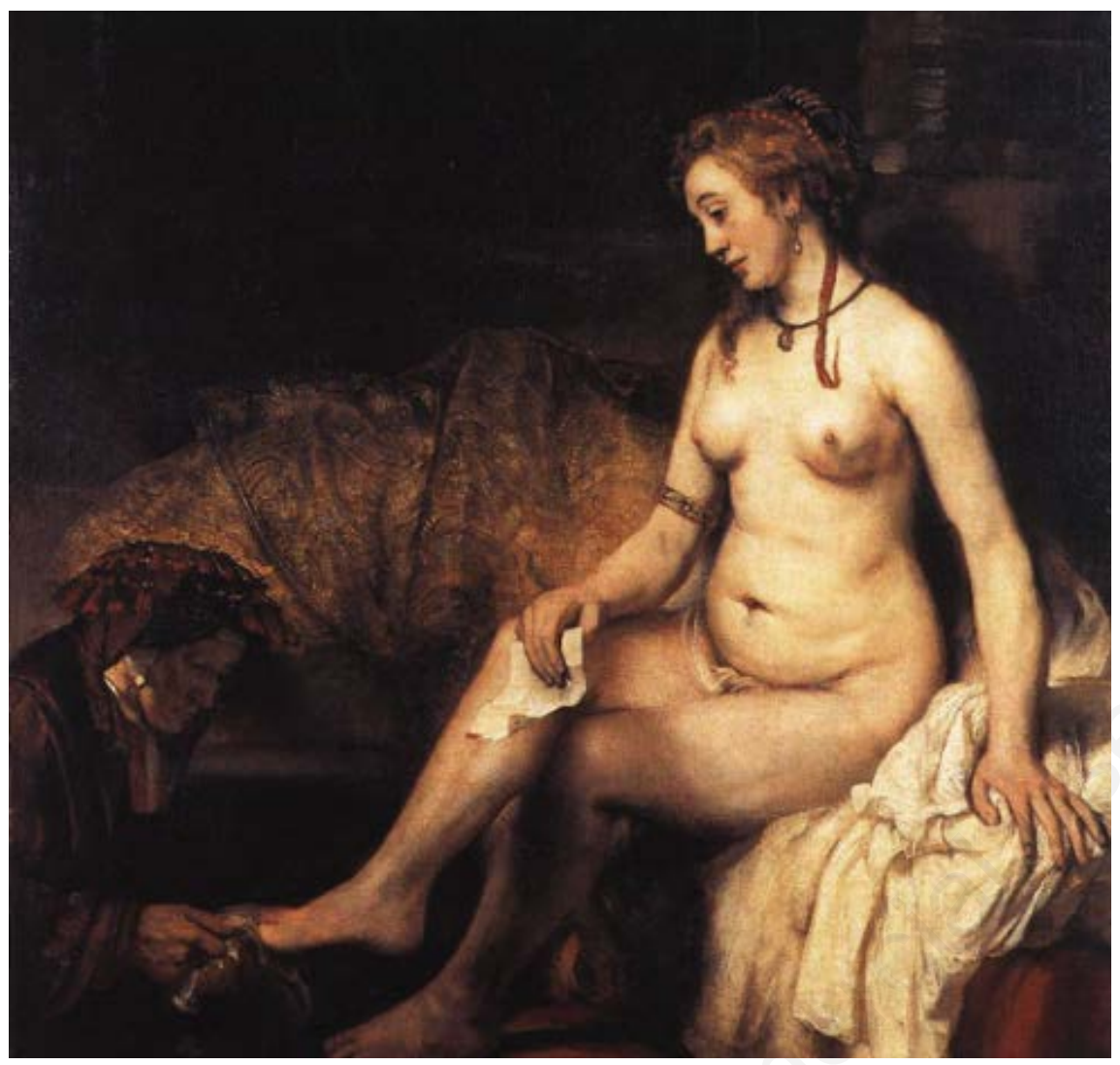

Figure 1. Bathsheba at her bath as painted by Rembrandt van Rijn in 1654, Louvre, Paris (reprinted, with permission, from the Bridgeman Art Library).

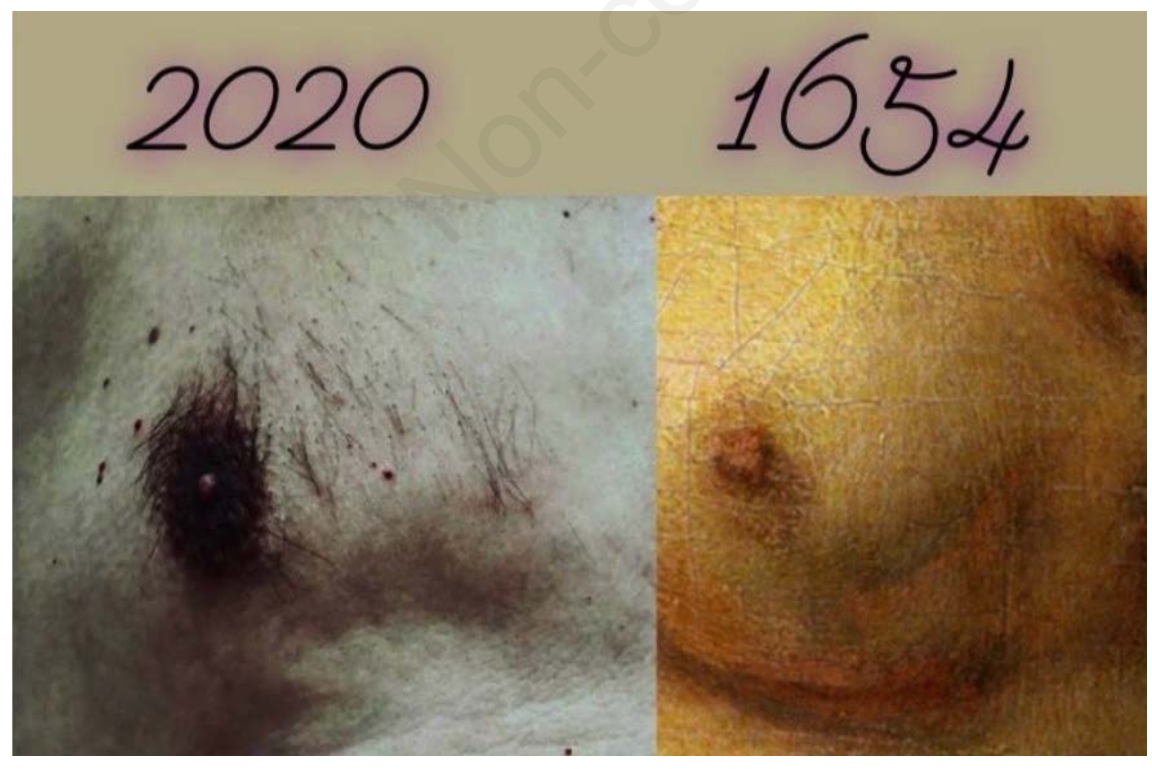

Figure 2. Left: Photograph of Zamboni's patient (male nurse's right breast showing discoloration with prominent bluish tints). Right: Magnification of the discoloration on Bathsheba's breast, as painted by Rembrandt (reprinted, with permission, from the Bridgeman Art Library, and from Paolo Zamboni paper).

\section{References}

1. Mondor H. Tronculite sous-cutanée subaiguë de la paroi thoracique antérolatérale Mem Acad Chir 1939;65:1258-71.

2. Mondor H, Bertrand I. [Thrombophlébites et périphlébites de la paroi thoracique antérieure]. Presse Med 1951;59:1533-5.

3. Helm JD Jr, Hodge IG. Thrombophlebitis of a dorsal vein of the penis: report of a case treated by phenylbutazone (Butazolidin). J Urol 1958;79:306-7.

4. Moskovitz AH, Anderson BO, Yeung RS, Byrd DR, Lawton TJ, Moe RE. Axillary web syndrome after axillary dissection. Am J Surg 2001;181:434-9.

5. Marsch W, Haas N, Stüttgen G. Mondor's phlebitis. A lymphovascular process. Dermatologica 1986;172:133-8.

6. Pugh CM, DeWitty RL. Mondor's disease. J Natl Med Assoc 1996;88:359-63.

7. Chiedozi LC, Aghahowa JA. Mondor's disease associated with breast cancer. Surgery 1988;103:438-9.

8. Amano M, Shimizu T. Mondor's disease: a review of the literature. Intern Med 2018;57:2607-12.

9. Braithwaite PA, Shugg D. Rembrandt's Bathsheba: the dark shadow of the left breast. Ann R Coll Surg Engl 1983;65:337-8

10. Bourne RG. Did Rembrandt's Bathsheba really have breast cancer? Aust N Z J Surg 2000;70:231-2.

11. Hayakawa S, Masuda H, Nemoto N. Rembrandt's Bathsheba, possible lactation mastitis following unsuccessful pregnancy. Med Hypotheses 2006;66:1240-2.

12. Zamboni P. The medical enigma of Rembrandt's Bathsheba. J Thromb Haemost 2020;18:1-3.

13. Bikdeli B, Madhavan MV, Jimenez D, et al. COVID-19 and thrombotic or thromboembolic disease: implications for prevention, antithrombotic therapy, and follow-up. J Amer College Cardiol 2020:164.

14. Belcaro G, Corsi M, Agus GB, et al. COVID: Thrombo-prophylaxis prevents events in home patients. Am J Card Cardiovasc Dis 2019;3:1-6.

15. Lang J, Yang N, Deng J, et al. Inhibition of sars pseudovirus cell entry by lactoferrin binding to heparan sulfate proteoglycans. PLoS One 2011;6:e23710.

16. Goeijenbier $M$, van Wissen $M$, van de Weg C, et al. Review: Viral infections and mechanisms of thrombosis and bleeding. $\mathrm{J}$ Med Virol 2012;84:1680-96. 